\title{
COMMUNITY AWARENESS AND PREFERENCES ON HEALTH FINANCING OPTIONS: THE CASE OF SONGEA RURAL DISTRICT, TANZANIA
}

\author{
Asia K Hussein ${ }^{1}$, MN Mlangwa ${ }^{2}$, and KN Hussein ${ }^{3}$
}

\begin{abstract}
Objectives: The objectives of this study were to assess community awareness and preferences on the alternative health financing mechanisms that have been introduced in the district.

Design: A cross sectional, household survey Setting: Songea Rural District, Ruvuma Region South Western Tanzania

Methods: Multistage random sampling procedure was used to select 6 villages that were included in the study. A total of 622 heads of households or their representatives were interviewed using an interviewer administered questionnaire. Computer data entry and analysis were done using EPI Info version 6.0 software programme.

Results: Community awareness on the Community Health Fund (CHF) and User Fees were high i.e. 94.9\% and 93.2\% respectively, while awareness on National Health Insurance Scheme (NHIS) was relatively low at $34.6 \%$. Most of the respondents used User Fees $(\mathbf{8 1 . 4 \% )}$ ) in financing their health care consumption and it was also the most preferred health financing mechanism (38.4\%) followed by CHF (30.5\%), however almost a fifth of the respondents, the majority of whom were peasants $(95.0 \%)$ preferred getting "free care".

Recommendations: Study recommendations include increasing community awareness on NHIS and ensuring proper identification of individuals who should be given fee waivers/ exemptions.
\end{abstract}

Keywords: Health care financing, community awareness, community preferences, Tanzania

\section{Introduction}

The provision and financing of health services in Tanzania was mainly the responsibility of the government for many years following independence in 1961 as was the case in many other developing countries (1). It is only during the last decade that this responsibility has been shared, following the introduction of health sector reforms which among other things have encouraged public private mix in provision of health care services and involvement of the community in the financing of their health care consumption form public health facilities through cost sharing $(2,3,4)$.

Introduction of cost sharing in the public health sector has been done in a stepwise manner with the intention of gradually accustoming the community to the idea of paying for their own health care. Cost sharing through user fees was first introduced at consultant and regional hospitals in 1993 and has gradually spread down to lower levels of the public health care system (1). The second cost sharing mechanism that was introduced was the Community Health Fund (CHF) in 1996 followed by the National Health Insurance Scheme (NHIS) in 2001.

User fees entails out of pocket expenditure at the point of health care consumption and include cost of consultation, investigations and prescribed medications. The government has established standard price schedules for different health facility levels which are used throughout the country. However, the cost that the consumer pays is only a small fraction of the actual cost as the government continues to subsidise the cost of health care.

Correspondence: Hussein AK, P.O. Box 65015, Muhimbili University College of Health Sciences, School of Public Health and Social Sciences. E-mail: ahussein@muchs.ac.tz

${ }^{1}$ School of Public Health and Social Sciences, ${ }^{2}$ Ilala, Municipal Medical Office of Health, ${ }^{3}$ Institute of Finance Management (IFM), Dar-Es-Salaam Tanzania
An exemption policy has been put in place to ensure that vulnerable population groups such as underfive year old children, pregnant women, the elderly, those suffering from chronic disease conditions and the indigent are not denied access to health care $(2,5)$.

The CHF is a district level pre-payment scheme for primary health care services targeted at rural populations and the informal sector. It was first piloted in Igunga District in 1996 and then rolled out in an additional 9 districts in 1998. Households pay an annual membership fee when they are most able to do so e.g. during harvest season; and this entitles them to unlimited access to a basic package of curative and preventive health services at participating health facilities (6). Each district establishes the amount that households would contribute and the government provides matching funds. Under the CHF arrangement, the indigent are provided free health care following an identification process by community members.

The NHIS is a mandatory risk pooling mechanism that has been initially targeted to people employed in the formal sector which initially covered central government employees (7). A contribution of $6 \%$ of the employee's salary is paid to the National Health Insurance Fund monthly with the government and the employee each contributing 3\%. The insured employee, their spouses and four children or legal dependants are entitled to a specified package of health care after six months of joining the scheme.

Songea Rural District in Southern Tanzania was among the first districts where the CHF was first rolled out in 1998. User fees were introduced at the same time of the introduction of CHF, while the NHIS was introduced later in the year 2001. The main objective of this study was to document community awareness and preferences on the three health care financing options that have been available for about four years to community members in Songea Rural District. 


\section{METHODOLOGY}

\section{Description of the study area}

Songea Rural District is located in Ruvuma Region in Southern Tanzania. The district covers an area of 33,925 $\mathrm{km}^{2}$ and is administratively divided into 7 divisions and 26 wards. The district has an estimated population of 408,314 (National Census, 2002) with a growth rate of $3.4 \%$. The majority of the residents are peasants. Health facilities in the district include one voluntary hospital; 7 health centres, $(6$ government, 1 voluntary organization owned) and 55 dispensaries (34 government, 18 voluntary organization and 3 privately owned).

\section{Study population}

The study population consisted of heads of households in Songea Rural District.

\section{Sample size and sampling:}

A convenient sample size of 600 subjects was established. Multistage random sampling was done to select 6 villages that were included in the study. A minimum of 100 heads of households per village were approached for interview.

\section{Study variables:}

The independent variables in the study were age, sex, marital status, household size, education, occupation, and religion of the respondents and size of the household. Dependant variables were awareness and preference of health financing mechanisms.

\section{Data collection procedures:}

Data were collected from representatives of households usually the head of the household using a pre-tested questionnaire that was translated into Kiswahili language for field use. The head of household was defined as the husband in a matrimonial household or any other adult person who was considered to be the head by other household members. When the head of the household was not present, the household was revisited the next day. If the head of household was absent the second time, the spouse or another adult person was interviewed. Four research assistants who had undergone training on how to administer the questionnaire helped during data collection.

\section{Ethical considerations}

Research clearance was obtained from Muhimbili University College of Health Sciences Research and Ethical Review Committee. Permission was obtained from all relevant regional and district authorities. Oral consent for interview was obtained from all respondents after giving them an explanation on the purpose of the study.

\section{Data processing and analysis}

Questionnaires were checked for any errors in filling at the end of each field day. Computer data entry was done using EPI info 6.0 computer software programme. Data analysis was done using the same program following data validation and cleaning. The Mantel Hansel chi-square test $(p<0.05)$ was used to determine any association between awareness and preference of the different health financing options and socio-economic characteristics of respondents.

\section{Results}

A total of 622 respondents were interviewed of whom 359 (57.7\%) were males and 263 (42.3\%) were females (see table 1). Their ages ranged between 18 to 86 years with the overall mean age being 39 years. The mean age of males was 41 years while that for females was 37 years. Almost three quarters $(73.8 \%)$ of respondents were married while $18.8 \%$ were single. The highest level of education attained by $61.3 \%$ of the heads of the households was complete primary education while only $1.2 \%$ had complete secondary education or above. Most of the respondents were peasants (79.6\%).

Table 1: Social demographic characteristics of study respondents $(\mathrm{N}=622)$

\begin{tabular}{|c|c|c|}
\hline Variable & No. & (\%) \\
\hline \multicolumn{3}{|l|}{ Sex } \\
\hline Female & 359 & $(57.7)$ \\
\hline Female & 263 & (42.3) \\
\hline \multicolumn{3}{|l|}{ Age (years) } \\
\hline$<20$ & 17 & $(2.7)$ \\
\hline $20-29$ & 165 & (26.5) \\
\hline 30-39 & 170 & (27.3) \\
\hline $40-49$ & 134 & $(21.5)$ \\
\hline $50-59$ & 73 & (11.7) \\
\hline$>59$ & 63 & $(10.1)$ \\
\hline \multicolumn{3}{|l|}{ Marital status } \\
\hline Single & 117 & (18.8) \\
\hline Married & 459 & (73.8) \\
\hline Cohabiting & 2 & $(0.3)$ \\
\hline Separated/ Divorced & 9 & (1.2) \\
\hline Widow & 35 & $(5.6)$ \\
\hline \multicolumn{3}{|l|}{ Level of Education } \\
\hline Informal & 50 & $(8.0)$ \\
\hline Primary incomplete & 96 & $(15.4)$ \\
\hline Primary complete & 378 & (60.8) \\
\hline Secondary Incomplete & 91 & (14.6) \\
\hline >Secondary complete & 7 & $(1.2)$ \\
\hline \multicolumn{3}{|l|}{ Occupation } \\
\hline Employed & 76 & $(12.2)$ \\
\hline Self employed & 51 & (9.2) \\
\hline Peasant & 495 & (79.6) \\
\hline
\end{tabular}

Table 2 shows that the majority of the respondents were aware of at least one health financing mechanism. The CHF was most commonly known (94.9\%) while the least known health financing mechanism was NHIS (34.6\%). The 
employed occupation category had higher proportions of individuals who were aware of the different health financing options compared to the other occupation categories. These findings are statistically significant $(\mathrm{p}<0.05)$.

From table 2 it is also seen that overall User Fees (38.4\%) was the most preferred health financing mechanism followed by CHF (30.5\%). However, while higher proportions of those who were self employed (62.7\%) and peasants (39.6\%) preferred User Fees, those who were employed preferred NHIS (73.7\%). Almost a fifth of the study respondents (119) preferred getting "free care", the majority of whom were from the peasant occupation category (95.0\%).

Table 2: Respondents' awareness and preferences of different health mechanisms by occupation status

\begin{tabular}{|c|c|c|c|c|c|c|c|c|}
\hline \multirow{3}{*}{ Variable } & \multicolumn{8}{|c|}{ Occupation Status } \\
\hline & \multicolumn{2}{|c|}{$\begin{array}{c}\text { Employed } \\
(N=76)\end{array}$} & \multicolumn{2}{|c|}{$\begin{array}{l}\text { Self Employed } \\
(\mathrm{N}=51)\end{array}$} & \multicolumn{2}{|c|}{$\begin{array}{l}\text { Peasant } \\
(\mathrm{N}=495)\end{array}$} & \multicolumn{2}{|c|}{$\begin{array}{c}\text { Total } \\
(\mathrm{N}=622)\end{array}$} \\
\hline & No. & $(\%)$ & No. & $(\%)$ & No. & $(\%)$ & No. & $(\%)$ \\
\hline \multicolumn{9}{|l|}{ Awareness } \\
\hline CHF & 75 & (98.7) & 50 & (98.0) & 465 & (93.9) & 590 & (94.9) \\
\hline User Fees & 74 & (97.4) & 47 & $(92.2)$ & 459 & (92.7) & 580 & (93.2) \\
\hline NHIS & 63 & (82.9) & 11 & (21.6) & 141 & (28.5) & 215 & (34.6) \\
\hline \multicolumn{9}{|c|}{ Preferred Option } \\
\hline CHF & 4 & (5.2) & 12 & (23.5) & 174 & (35.2) & 190 & (30.5) \\
\hline User Fees & 11 & (14.5) & 32 & (62.7) & 196 & (39.6) & 239 & (38.4) \\
\hline NHIS & 56 & (73.7) & 1 & (2.0) & 12 & (2.4) & 69 & (11.1) \\
\hline
\end{tabular}

Respondents who were aware of the different health financing alternatives available to the community in the district were asked to mention their source of information on the health financing alternatives. From table 3 it is seen that the most common source of information on different health financing mechanisms for respondents in the study area were health service providers followed by village meetings. The radio was an important source of information for NHIS. Relatives, neighbors and newspapers were least mentioned as sources of information on any of the health financing mechanisms. These findings are statistically significant $(\mathrm{p}<0.05)$.

Table 3: Respondent's sources of information on different health financing mechanisms

\begin{tabular}{lcccccccc}
\hline Source of Information & \multicolumn{9}{c}{ Health Financing Mechanism } & \multirow{3}{*}{ Total } \\
& CHF & \multicolumn{5}{c}{ User Fees } & NHIS & \\
& No. & $(\%)$ & No. & $(\%)$ & No. & $(\%)$ & \\
\hline Health Service Providers & 246 & $(41.7)$ & 271 & $(46.7)$ & 77 & $(36.3)$ & 594 \\
Village Leaders/ Meetings & 250 & $(42.4)$ & 360 & $(44.8)$ & 23 & $(10.9)$ & 533 \\
Radio & 68 & $(11.5)$ & 34 & $(6.0)$ & 84 & $(39.6)$ & 186 \\
Relatives/ neighbours & 11 & $(1.9)$ & 9 & $(1.5)$ & 19 & $(9.0)$ & 39 \\
Newspapers & 15 & $(2.5)$ & 6 & $(1.0)$ & 9 & $(4.2)$ & 20 \\
\hline
\end{tabular}

Respondents were asked to provide spontaneous responses on why they preferred a particular health financing mechanism. Table 4 shows reasons given by respondents. The most common reasons given for preferring
CHF were because it is affordable and that one has to pay only once per year (i.e. $95.8 \%$ for both) and that there is a possibility of paying in installments (35.8\%). The top two reasons given by those who prefer NHIS were that they could go and get treatment whenever they got sick (94.2\%) and that they do not have to pay directly out of their pockets for their health care consumption (91.3\%).

The majority of the respondents who preferred User Fees mentioned that this was because they only have to pay money when they or a family member gets sick (97.1\%) and that they can visit a health facility of their choice when they fall sick (84.5\%).

Table 4: Reasons for preference of the different health financing mechanisms

\begin{tabular}{llll}
\hline $\begin{array}{l}\text { Health } \\
\text { Financing } \\
\text { Mechanism }\end{array}$ & Reasons for Preference & No. & $\mathbf{( \% )}$ \\
\hline $\begin{array}{l}\text { CHF } \\
\text { (N=190) }\end{array}$ & Affordable & & \\
& Payment only once per year & 182 & $(95.8)$ \\
& Can pay in installments & 182 & $(95.8)$ \\
& & 68 & $(35.8)$ \\
User Fees & Pay money only when sick & 232 & $(97.1)$ \\
$\mathbf{N = 2 3 9 )}$ & Have a choice of where to go when sick & 202 & $(84.5)$ \\
& Rarely get sick & 176 & $(73.6)$ \\
NHIS & Whenever sick I get treatment & 65 & $(94.2)$ \\
$\mathbf{( N = 6 9 )}$ & Don't pay directly out of pocket & 63 & $(91.3)$ \\
& Employer deduct my salary for contribution & 60 & $(86.9)$ \\
\hline
\end{tabular}

From table 5 it is seen that overall User Fees were used as a health financing mechanism by the majority of the respondents (81.4\%)

Table 5: Health financing mechanism used to obtain health care services by occupation status of the respondents

\begin{tabular}{|c|c|c|c|c|c|c|c|c|}
\hline \multirow{3}{*}{$\begin{array}{l}\text { Health } \\
\text { Financing } \\
\text { Mechanism }\end{array}$} & \multicolumn{6}{|c|}{ Occupation Status } & \multicolumn{2}{|c|}{ Total } \\
\hline & \multicolumn{2}{|c|}{ Employed } & \multicolumn{2}{|c|}{$\begin{array}{c}\text { Self } \\
\text { Employed } \\
\end{array}$} & \multicolumn{2}{|c|}{ Peasant } & & \\
\hline & No. & $(\%)$ & No. & $(\%)$ & No. & $(\%)$ & No. & $(\%)$ \\
\hline CHF & 8 & (10.7) & 3 & (5.9) & 36 & (7.3) & 47 & (7.6) \\
\hline User Fee & 27 & (36.0) & 46 & $(90.2)$ & 432 & (87.4) & 505 & (81.4) \\
\hline NHIS & 40 & (53.3) & 2 & (3.9) & 26 & (5.3) & 68 & (11.0) \\
\hline Total & 75 & (100) & 51 & (100) & 494 & $(100)$ & $620^{*}$ & (100) \\
\hline
\end{tabular}

*NB: 2 respondents reported that they had been exempted from payment.

\section{Discussion}

The participation of the community in contributing funds for their own health care consumption is one of the fundamental principles of the ongoing financial reforms in the health sector (8). It has been argued that funds should be raised from the people according to their ability to pay and spent according to health care needs in order to ensure equitable access, efficient and effective care. During the last decade, the government of Tanzania has introduced three alternative health financing mechanisms in its health facilities i.e. User Fees, CHF and NHIS in order to raise 
additional funds for the public health sector while ensuring that Tanzanians from all socioeconomic groups are not denied access to quality health care.

Findings of this study show that the majority of the respondents were aware of two of the three alternative financing mechanisms that have been introduced i.e. CHF (94.9\%) and User Fees (93.2\%). Awareness on NHIS however, was relatively low with only just over a third of the respondents (34.6\%) mentioning having heard about it. The lower level of awareness of NHIS among the study respondents can be expected because it was the last alternative health financing mechanism to be introduced in Singida rural district, and also the fact that NHIS has been targeted to people working in the formal sector while most of the respondents in this study were peasants. Health service providers and village meetings were established as being important sources of information on alternative health financing mechanisms with radio and newspapers not being prominent sources. Similar findings have been established elsewhere, and this underlines the importance of ensuring health workers and local authorities are well informed on the various alternative health financing mechanisms so that they are in a position to pass correct and comprehensive information to the public (9).

Most available literature on health sector financing reforms has focused on ability and willingness to pay for health care which was once provided "free of charge" by developing countries governments and there is scarcity of literature on community preferences on the health financing alternatives that have since been introduced. Study findings show that User fees was the alternative health financing mechanism that was used by the majority of the respondents (81.4\%) in obtaining health care. When respondents were asked to mention what was their most preferred health financing alternative a high proportion mentioned User Fees (38.4\%) followed by CHF (30.5\%). This is contrary to the findings of a study from North West Tanzania which established that respondents favoured a local health insurance system over User fees in obtaining district health services (8).

The fact that only $11.1 \%$ of the respondents mentioned that they preferred NHIS could have been influenced by their low level of awareness on this health financing alternative among study respondents, however a high proportion of respondents in the employed occupation category $(73.7 \%)$ mentioned NHIS as the health financing mechanism that they preferred. This is contrary to our expectations as there have been several reported incidents in the local news media where civil servants mainly teachers have expressed their dissatisfaction with the operations of the NHIS. This could be a reflection on the ongoing efforts on increasing member awareness on how the NHIS operates.

Almost a fifth of the study respondents (19.1\%) mentioned that they preferred getting health care "free of charge". The majority of the respondents in this study were peasants (79.6\%) and their preferring "free care" is a reflection on their socio-economic status and their ability to pay for health care. This is an important observation because it implies that the introduction of cost recovery schemes in the health sector could limit health care access for a big proportion of the community an observation that has already been established by study reports from other parts of the country $(3,4,10)$. In order to ensure that poor households are not excluded from accessing appropriate health care, Steinwachs (2002) argues for the need of introducing a combination of different health financing networks i.e. church schemes and local area networks in addition to the three cost recovery schemes that have already been introduced in the public health sector. Although the importance of having an effective waiver system that would ensure basic health care access to all community members who are not able to pay has been discussed before by several authors $(2,3,5,9,11)$ it cannot be overemphasized in this article as well.

\section{Study recommendations:}

In order to enhance community participation in payment for health care, efforts have to be made to educate and sensitise them on all the cost recovery programs that exist. In the study area specifically efforts need to made to raise community awareness on NHIS

There is need to ensure that all community members have access to quality health care when they need it. The identification of "poor" households in an area where everyone is considered poor should not be a problem if the local community is involved in identifying who should get waivers.

\section{References}

1. Ministry of Health. Health Sector Reform: Plan of Action 1996-1999. Dar-EsSalaam, Tanzania; 1996.

2. Newbrander $W$ and Sacca S. Cost sharing and access to health care for the poor: Equity experiences in Tanzania. Management Sciences for Health. USAID. USA; 1996.

3. Hussein A and Mujinja, PGM. Impact of user charges on government health facilities in Tanzania. East African Medical Journal 1997; 74(12):751-57.

4. Quaye RK. Paying for health services in East Africa. A research note. Social theory and Health 2004; 2:94-105.

5. Laterveer $L$, Munga $M$ and Schwerzrel $P$. Equity implication of health sector

6. user fees in Tanzania. A report commissioned by Research for Poverty Alleviation (REPOA); 2004.

7. Chee G, Smith K and Kapiga A. Assessment of Community Health Fund in Hanang district, Tanzania. Bethesda, MD. The Partnership for Health Reform Plus Project. Abt. Associates; 2002.

8. Humba E. Social Health Insurance. Implementing social security health care. The experience of the National Health Insurance Fund. A paper presented at the International Social Security Association, Lusaka, Zambia; 2005. http:www.issa.int/pdf/Lusaka05/2humbapdf. Accessed $20^{\text {th }}$ September 2005.

9. Walraven G. Willingness to pay for district health services in rural Tanzania. Health Policy and Planning 1996; 11(4):428-37.

10. Mubyazi GM, Massaga JJ, Njunwa KJ et al. Health financing policy reform in Tanzania: payment mechanisms for poor and vulnerable groups in Korogwe district. Small Applied Research Report No. 13, Bethesda, MD. Partnerships for Health Project. Abt. Associates Inc.; 1999.

11. Steinwachs L. Extending health protection in Tanzania. Networking between health financing mechanisms. ESS Paper No. 7, Geneva. ILO ISBN 92-2-1131866; 2002.

12. Bonu S, Rani $M$ and Bishai $D$. Using willingness to pay to investigate regressiveness of user fees in health facilities in Tanzania. Health Policy and Planning 2003; 84(4): 370-382. 